\title{
Assessing Coral Community Recovery from Coral Bleaching by Recruitment in Two Reserves in Kenya
}

\author{
Visram S., Mwaura J. and Obura D.O. \\ CORDIO East Africa (Coastal Oceans, Research and Development in the Indian Ocean), P.O. Box 10135 \\ Mombasa 80101 Kenya
}

Keywords: Coral Bleaching, Coral Recruitment, Kenya, Kiunga Marine National Reserve, Mombasa Marine National Park and Reserve and Reef Recovery

\begin{abstract}
In 2003 and 2005, studies were carried out on the density of small coral colonies $(<10$ $\mathrm{cm}$ ) on three reefs in the Mombasa Marine National Park and Reserve on the southern fringing reef system of Kenya, and on three reefs in the Kiunga Marine National Reserve in the north of the country. All the study sites were impacted by a major coral bleaching event in 1998. A total of 28 coral genera from 12 families were recorded, of which 17 genera were recorded on both northern and southern sites. Two or three genera of corals contributed 50-60\% of all small colonies in both regions, with Porites, Coscinarea and Pocillopora the main contributors of small colonies in Kiunga, and Pocillopora being the most abundant genus of small corals in Mombasa in both years. The densities of small colonies were lowest at the northern sites, and small colonies of genera of corals that suffered from high bleaching and mortality during the El Niño Southern Oscillation in 1998 were less abundant in the north. These northern reefs are relatively isolated from sources of coral larvae from reefs in the south, and are seasonally influenced by nutrient-rich, cooler water due to the influence of the Somali Current and the northeast monsoon winds. The data presented here support our preliminary assessment that these northern reefs are less likely to recover by natural recruitment. These reefs are therefore more vulnerable to environmental perturbation such as the conditions that elicited coral bleaching on the study reefs in 1998.
\end{abstract}

\section{INTRODUCTION}

The coral reefs of Kenya occur in two distinct marine regions, the fringing reef system in the south of the Kenya coast, and the patch reefs in northern Kenya. A dominant feature of the southern Kenya coastline is the almost continuous fringing reef that stretches between the town of Malindi and the border with Tanzania (Sheppard \& Wells 1988) shown in Figure 1. The prevailing ocean current in this part of the coastline is the warmwater, north-flowing East African Coastal Current (EACC). Coral reefs in the northern Kenya, near the island settlements of Lamu, Pate and Manda, and those in the Kiunga Marine National Reserve comprise discontinuous and patchy reefs within a system of barrier islands, mangrove forests and sea grass beds (Obura 2002, Church \& Obura 2005). These northern reefs are seasonally bathed by relatively cool, nutrient-rich, water from the south-flowing Somali Current (Johnson et al. 1982; McClanahan 1988). The region of approximately $100-150 \mathrm{~km}$ between these two major reef regions of Kenya is largely devoid of coral reefs due to the discharge of freshwater and sediments from two of Kenya's major rivers, the Sabaki and the Tana (Obura 2001a).

Coral reefs in the western Indian Ocean were severely impacted by coral bleaching and mortality during the 1997-98 El Niño Southern Oscillation 
(ENSO) (Wilkinson et al. 1999, Goreau et al. 2000). In Kenya, the decline in percent of live coral cover was most pronounced on protected reefs, i.e. marine parks, where extractive use is prohibited, on the southern fringing reef system, from $40 \%$ prior to bleaching, to less than $15 \%$ after the bleaching event (Obura 2002). Prior to the 1997-98 bleaching event, coral cover on the northern reefs was about $15 \%$. This is slightly less than on fished reefs in the south (Obura 2002), which include marine reserves where traditional fishing methods are allowed and non-protected areas. Coral cover on almost al Kenyan coral reefs studied had declined to around $10 \%$ after the bleaching event (McClanahan et al. 2002). Recovery of reefs to date in Kenya has been moderate and patchy (Obura 2002). A positive recovery trajectory is reported for marine parks and fished reefs (reserves and non-protected areas) in southern Kenya, but for less than half of the northern reefs surveyed (Obura 2002, Church and Obura 2005). This differential recovery appears to suggest that, compared to the southern fringing reef, reefs in northern Kenya may be less resilient to environmental perturbation, such as predicted recurrences of elevated seawater temperature conditions similar to 1998 (Sheppard 2003).

Coral recruitment studies form an essential component of the coral reef monitoring programme undertaken in Kenya. The data generated help to assess the potential for recovery of coral reefs in the aftermath of major disturbances, including the ENSO-associated bleaching of 1997-98. Early life stages are thought to be more susceptible than adults to environmental stresses such as sediments and eutrophication (Ward \& Harrison 1996), and monitoring coral recruits may provide an early warning of potential damage to reefs after disturbances. Reefs in northern Kenya are predicted to have a lower density and diversity of coral recruits than reefs in southern Kenya, given their relative isolation from the main coral reef areas of East Africa in Tanzania and Mozambique and the seasonal influence of nutrient-rich water from the Somali Current, (Obura, in review). Furthermore, we predict that bleaching-susceptible corals that suffered near-complete mortality on Kenyan reefs following the 1997-98 bleaching, including corals from the genera Pocillopora and Acropora (Obura 2001b), recruit more strongly to Kenya's southern reefs, with coral larvae carried by the EACC from source reefs farther south. The purpose of this study was to make an initial test of the predictions above by comparing patterns of the abundance of small coral colonies (recruits) between reefs in Mombasa, near the centre of the southern fringing reef system of Kenya and those in the Kiunga Marine National Reserve in northern Kenya.

\section{MATERIALS AND METHODS}

Surveys of small coral colonies were carried out at six sites in Kenya. Three sites were located near the centre of the fringing reef system in southern Kenya in the Mombasa Marine National Park (39 $45^{\prime}$ E, $4^{\circ} 00$ ' S): Coral Gardens (site 1) and the Mombasa Marine National Reserve (39 $44^{\prime}$ 'E, $4^{\circ} 01^{\prime}$ S): Ras Iwatine (site 2), and Nyali (site 3). Three sites were situated in the north in the Kiunga Marine National Reserve (4130' E, 200'S): Shimo la Tewa (site 6), Mkokoni (site 5) and Boso (site 4) (see Figure 1). Study sites were selected on the basis of similarity in hydrographic features including depth (mean low water, i.e. the lowest average level water reaches on an outgoing tide, 1-3 metres) and distance from shoreline. Site 1 was situated in a marine protected area and was the only site free of fishing pressure.

A highly visible nylon rope of length $56.4 \mathrm{~cm}$ was weighted at one end, and placed haphazardly on hard reef substrate at the study location. When rotated around the weighted end, the rope formed a circular sample area of one square metre in area. Sample sizes ranged from between 13 and 30 sample areas per site per year. The total number of 'small colonies', defined as having a maximum diameter of less than $10 \mathrm{~cm}$, in each sample area was scored, as was their genus. Remnants of once formerly large colonies were not included. Sampling at all sites was carried out for two years (2003 and 2005), except for site 2, where data are for 2003 were not collected. Data were analysed for significant differences in the density of small colonies between regions using nonparametric and descriptive statistics in the statistical package MINITAB version 10.1. The distribution of corals with high bleaching susceptibility in the northern and southern sites was tested using Chisquare test.

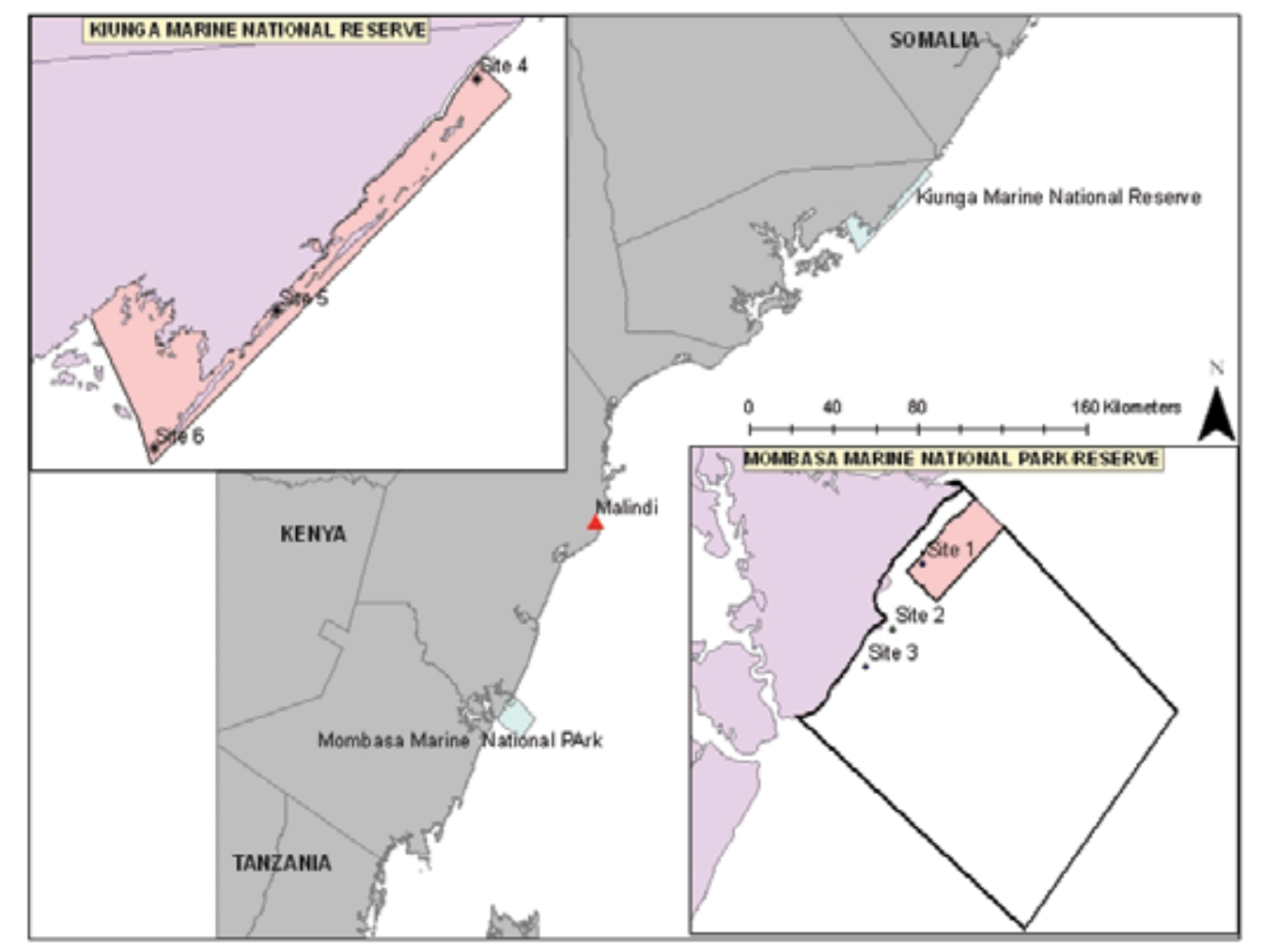

Fig. 1. The locations in Kenya where the study was conducted. Three sites were selected in each of the two localities the Kiunga Marine National Reserve in northern Kenya, and in the Mombasa Marine National Park and Reserve on the southern Kenya coastline

\section{RESULTS}

\section{Density of Small Colonies}

In 2003, the site with the highest density of small colonies was site 6 , located in the north $(5.33 \pm 3.60$ $\mathrm{m}^{-2}$, mean $\left.\pm 1 \mathrm{SD}\right)$, followed by site $3(4.85 \pm 2.97$ $\left.\mathrm{m}^{-2}\right)$ and site $1\left(3.00 \pm 1.84 \mathrm{~m}^{-2}\right)$ in the south (Figure 2). The two sites with the lowest densities of small colonies in 2003 were site $5\left(2.07 \pm 1.91 \mathrm{~m}^{-2}\right)$ and site $4\left(0.60 \pm 0.83 \mathrm{~m}^{-2}\right)$, both among the northern reefs. The three sites with the highest densities of small colonies of corals in 2005 were site 2 (5.95 $\pm 2.15), 3(5.30 \pm 1.89)$ and site $1(5.00 \pm 2.27)$, all at southern reefs. Once again, the two sites with the lowest density of small colonies in 2005 were the northern sites $5(1.63 \pm 1.63)$ and $4(0.91$ \pm 0.90 ). When data were compared for significant differences in densities of small colonies between regions (north versus south), the southern sites had significantly higher densities of small colonies in
2003 (Man-Whitney U test, $\mathrm{W}=5962.5, \mathrm{p}<0.01$ ) and in $2005(\mathrm{~W}=21844, \mathrm{p}<0.001)$

\section{Diversity of Small Colonies}

A total of 28 genera of small colonies of coral, representing 12 families were recorded during the study (Table 1), of which 17 genera were common to both northern and southern sites, 4 were recorded only in the north, and 7 were exclusive to the south. There were similarities in the patterns observed in both regions; between 2-3 coral genera contributed $50-60 \%$ of all small colonies (Figure 3). However the dominant genera differed between regions. In the south, Pocillopora were the dominant small colonies in 2003 and in 2005, whereas the dominant small colonies on northern sites were Porites, Coscinaraea and Pocillopora in descending order of dominance for both years of the study. Corals recorded from both regions were divided into two categories according to their bleaching responses during the 1997-98 ENSO (see Obura 2001b). These 


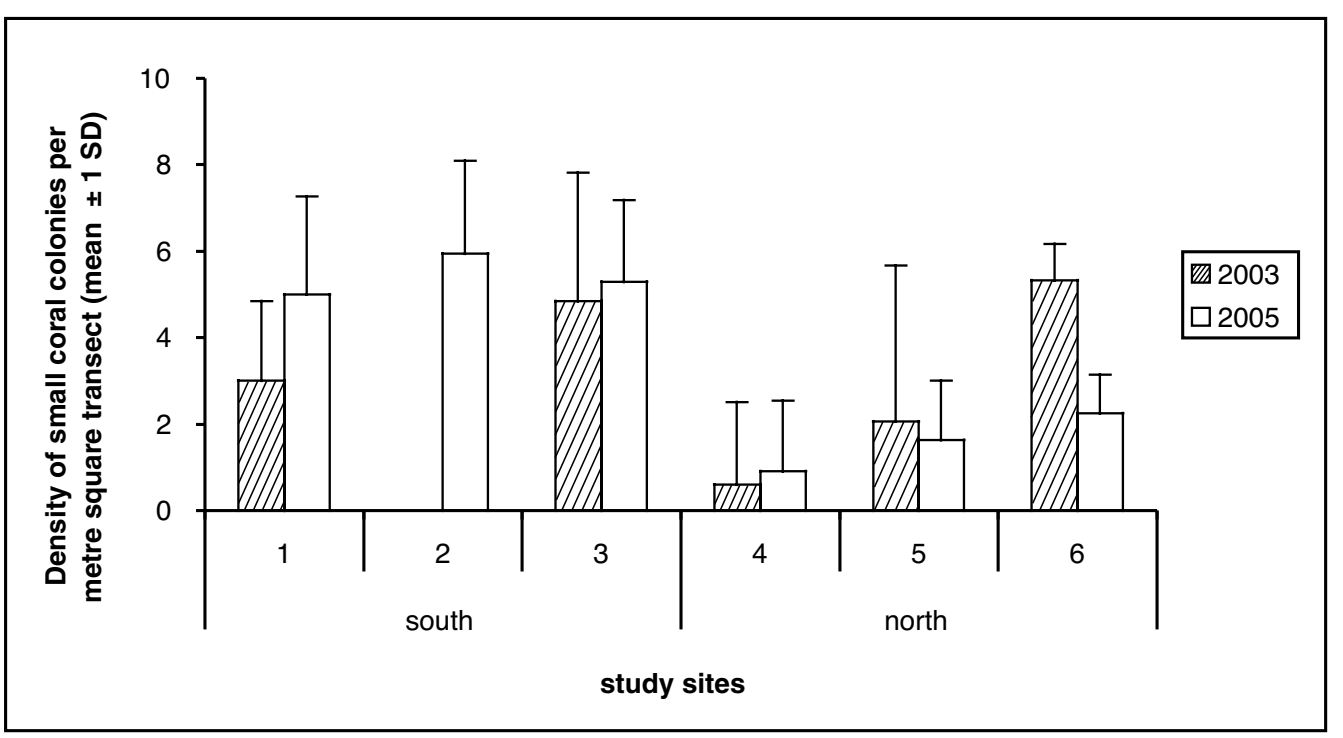

Fig. 2. The mean density of small coral colonies on reefs in the north and south of Kenya. Error bars are \pm 1 SD. Data were collected from three sites in the south (C: Coral Gardens; R: Ras Iwatine; N: Nyali) and three in the north (M: Mkokoni; S: Shimo la tewa, B. Boso). Data were collected in 2003 and 2005 for all reefs except site 2, for which data are available for 2005. Total number of sample areas per site per year varied between 13 and 30

included corals that underwent high bleaching and mortality (Acropora and Pocillopora), and the remaining corals that either were resistant to bleaching stressors and suffered little or no intermediate bleaching and mortality responses. A Chi-square test was carried out on small colonies of corals. The highly bleaching susceptible group, comprising Acropora and Pocillopora, were more abundant on southern sites than could be expected by chance $\left(\chi_{(1)}^{2}=43.146, p<0.001\right)$.

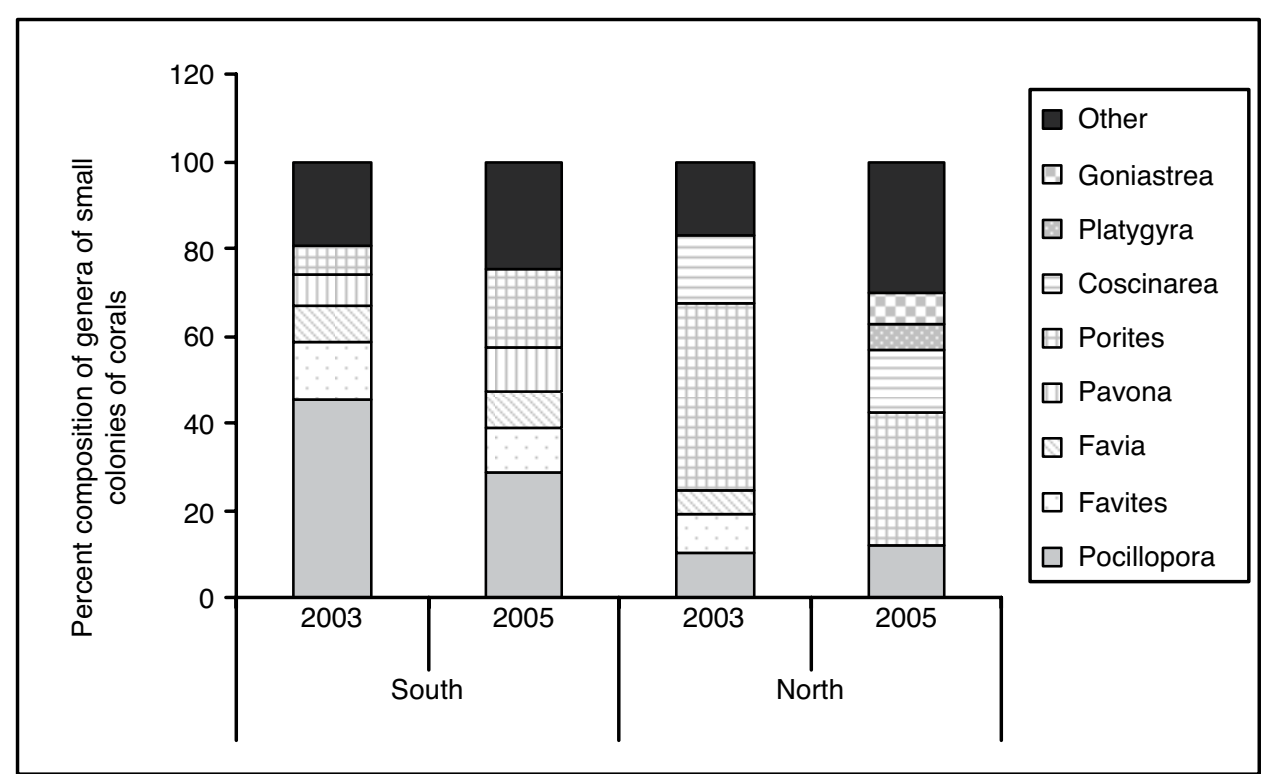
Fig. 3. The five dominant coral recruit genera scored in the south and north of Kenya in 2003 and 2005 . The data were obtained
from three sites in the north and two sites in the south for 2003, and at three sites each in the south and north in 2005
Table 1. The percent composition of small coral colonies from northern and southern reefs in Kenya in 2003 and 2005. Genera in bold print were recorded exclusively in the south or the north. n=number of reefs surveyed

\begin{tabular}{|c|c|c|c|c|c|}
\hline \multirow[t]{3}{*}{ Family } & \multirow[t]{3}{*}{ Genus } & \multicolumn{2}{|c|}{ South } & \multicolumn{2}{|c|}{ North } \\
\hline & & 2003 & 2005 & 2003 & 2005 \\
\hline & & $\mathrm{n}=2$ & $\mathrm{n}=3$ & $\mathrm{n}=3$ & $\mathrm{n}=3$ \\
\hline \multirow[t]{3}{*}{ Acroporidae } & Acropora & 2.91 & 2.08 & 0.00 & 0.86 \\
\hline & Astreopora & 0.00 & 0.30 & 0.00 & 0.00 \\
\hline & Montipora & 0.00 & 0.30 & 0.84 & 4.31 \\
\hline \multirow[t]{3}{*}{ Agariciidae } & Gardineroseris & 0.00 & 0.30 & 0.00 & 0.00 \\
\hline & Leptoseris & 0.00 & 0.00 & 0.00 & 0.86 \\
\hline & Pavona & 6.80 & 10.68 & 3.36 & 4.31 \\
\hline Dendrophylliidae & Turbinaria & 0.00 & 0.00 & 0.00 & 1.72 \\
\hline \multirow{9}{*}{ Faviidae } & Cyphastrea & 0.00 & 0.30 & 0.00 & 0.86 \\
\hline & Echinopora & 0.97 & 1.78 & 0.84 & 1.72 \\
\hline & Favia & 8.74 & 8.01 & 5.04 & 2.59 \\
\hline & Favites & 12.62 & 10.09 & 9.24 & 3.45 \\
\hline & Goniastrea & 0.00 & 0.59 & 2.52 & 6.90 \\
\hline & Leptastrea & 0.00 & 0.30 & 0.00 & 0.00 \\
\hline & Montastrea & 0.00 & 0.00 & 0.00 & 0.86 \\
\hline & Platygyra & 2.91 & 2.37 & 4.20 & 6.03 \\
\hline & Plesiastrea & 0.00 & 0.59 & 0.00 & 5.17 \\
\hline Fungiidae & Fungia & 0.97 & 0.59 & 0.00 & 0.00 \\
\hline Merulinidae & Hydnophora & 3.88 & 2.67 & 2.52 & 0.00 \\
\hline \multirow[t]{2}{*}{ Mussidae } & Acanthastrea & 0.00 & 0.89 & 0.00 & 0.00 \\
\hline & Lobophyllia & 2.91 & 0.00 & 2.52 & 0.00 \\
\hline Oculinidae & Galaxea & 3.88 & 7.42 & 0.00 & 1.72 \\
\hline Pectiniidae & Echinophyllia & 0.00 & 0.00 & 0.00 & 0.86 \\
\hline Pocilloporidae & Pocillopora & 45.63 & 28.78 & 10.08 & 12.07 \\
\hline \multirow[t]{3}{*}{ Poritidae } & Alveopora & 0.00 & 0.30 & 0.00 & 0.00 \\
\hline & Goniopora & 0.97 & 2.97 & 0.00 & 0.86 \\
\hline & Porites & 6.80 & 17.80 & 42.86 & 30.17 \\
\hline \multirow[t]{2}{*}{ Siderastreidae } & Coscinaraea & 0.00 & 0.59 & 15.97 & 14.66 \\
\hline & Psammocora & 0.00 & 0.30 & 0.00 & 0.00 \\
\hline Total number of transects & & 27 & 62 & 45 & 73 \\
\hline Total number of small colonies & & 103 & 337 & 119 & 116 \\
\hline
\end{tabular}

\section{DISCUSSION AND CONCLUSION}

Densities of small corals recorded in this study were at the low end of those reported in earlier studies. Tamelander (2002) reported average densities of corals smaller than $10 \mathrm{~cm}$ of 4.05 to $21.4 \mathrm{~m}^{-2}$ Highest densities were recorded in the Mombasa Marine Park, though quadrats with low densities were recorded at all sites from south to north Kenya. The data presented here indicate that if the density of small colonies serves as a reasonable proxy for recruitment rate, then coral reefs in the Mombasa Marine National Park/Reserve near the centre of the southern fringing reef of Kenya have higher rates of coral recruitment than the northern reefs in the Kiunga Marine National Reserve. There are at leas two possible explanations for this observation. The first involves the influence of cool, nutrient rich water in the north due to the interaction between the Somali Current system and the monsoon trade winds (Johnson et al. 1982, McClanahan 1988). High levels of nutrients are known to promote the growth of turf and macro-algae on reef substrates at the expense of slower-growing corals (Goreau et al. 2000), and studies have shown that reefs in the Kiunga Marine National Reserve are algadominated (Samoilys 1988, Church and Obura 2005). Increased competition with algae at these northern reefs is likely to depress the growth and survival of newly settled corals, as well as prevent settlement of larvae from the water column. In addition, the relatively cool temperatures in 
the north may suppress reproduction in local populations of adult corals, limiting the supply of coral larvae.

The second possibility for the lower recruitment of corals on the northern reefs of Kenya involves their relative isolation from the centre of coral biodiversity in East Africa, in southern Tanzania and Mozambique. The prevailing current in Eas Africa, the EACC, is predicted to play an important role in dispersal, carrying with it coral larvae as it flows northwards along the east coast of Africa. As the distance from coral-rich source reefs increase and as coral larvae settle on reef substrate, the concentration and diversity of larvae carried by the current will decrease. Although planulae larvae of some coral species are thought to survive approximately 100 days and successfully settle (Richmond 1987), the probability of survival of larvae borne by the current is likely to decline with increasing distance and duration. These factors, combined with the large distance of non-reef habitat separating the southern fringing reef and the northern patch reefs of Kenya (Obura 2001a), are predicted to have a strong dilution effect on the concentration of coral larvae carried by the EACC to the reefs in the Kiunga Marine National Reserve.

Establishing the relative contribution of the two primary factors described above is not straightforward. Indeed, both factors are likely to work simultaneously to varying degrees in shaping the patterns reported here. Some information may be gleaned from closer inspection of the patterns of density of small colonies. A conspicuous feature in the data is the higher density of small colonies of corals with high bleaching susceptibility, namely Acropora and Pocillopora, on the southern study localities. These corals suffered from high bleaching-related mortality during the 1997-98 ENSO event, and were virtually eliminated from all Kenyan reefs (Obura 2001b). Subsequent recruitment of these corals to the study sites is almost certainly from source reefs farther south in East Africa, where density and diversity of susceptible genera including Acropora, Pocillopora Stylophora and Seriatopora remained higher afte the 1997-98 bleaching (Obura, unpublished data). Settlement of Pocilloporidae larvae on artificial settlement tiles is particularly high in Mombasa, where they form $76 \%$ of all spat (Obura et al. 2005). Relative isolation of the northern sites is likely to have been an important determinant of the low recruitment of bleaching-susceptible corals to these reefs. Here the origin of the majority of coral recruits is predicted to be from reproduction of adult colonies in the local population. The recurring dominance of small colonies of Porites and Coscinaraea on northern sites in both years of the study reflects the community composition of the reefs (Obura, in review) and are most likely locally derived, although this has not been determined. An independent dataset on coral recruitment in the Kiunga Marine National Reserve made the same findings (Obura, in review), concluding that isolation from the southern reefs and recruitment limitation of reefs in the KMNR contributed to the collapse in the populations of the bleaching susceptible genera Acropora and Pocillopora after the ENSO-related coral mortality of 1997-98.

A shortcoming of this study is that all the southern sites selected for study were situated in the Mombasa Marine National Park and Reserve system, near the centre of the fringing reef of southern Kenya. A wider spread of reefs distributed across the length of the fringing reef is more desirable, as was done for the northern reefs, as it would allow a more balanced comparison of coral recruitment patterns between the northern reefs and the southern fringing reef of Kenya. If the results from Mombasa serve as a reasonable proxy for recruitment rates at other sites in the south, then our preliminary assessment is that when compared with the southern fringing reef of Kenya, reefs in the Kiunga Marine National Reserve have a lower potential for recovery by coral recruitment, and are therefore more vulnerable in the event of a recurrence of major coral bleaching.

Acknowledgements - We would like to acknowledge Kenya Wildlife Service (KWS) for permission to conduct coral recruitment surveys in the marine parks and reserves of Kenya. Our thanks go also to the World Wide Fund for Nature, Kiunga Marine Reserve project. Sida/SAREC provided financial support for this work.

\section{REFERENCES}

Church, J. \& Obura, D. (2005) Sustaining Cora Reef Ecosystems and their Fisheries in the Reef Ecosting Kiunga Marine Nation Reserve, Lamu, Kenya. Proceeding
Symposium

Goreau, T., McClanahan, T., Hayes, R. \& Strong, A. (2000) Conservation of coral reefs after the 1998 global bleaching event. Conservation Biolog $14,5-15$

Johnson, D., Nguli, M. \& Kimani, E. (1982) Response to annually reversing monsoon winds at the southern boundary of the Somali Current. Deep Sea Research 29, 1217-1227

McClanahan, T. (1988) Seasonality in East Africa's coastal waters. Marine Ecology Progress Series 44, 191-199

McClanahan, T., Maina, J. and Pet-Soede, L. (2002) Effects of the 1998 coral mortality event on Kenyan coral reefs and fisheries. Ambio 31,543-550

Obura, D.O. (2001a) Kenya. Marine Pollution Bulletin 42, $1264-1278$

Obura, D.O. (2001b) Can differential bleaching and mortality among coral species offer useful indicators for assessment and management of reefs under stress? Bulletin of Marine Science 69, 777-791

Obura, D.O. (2002) Status of Coral Reefs in Kiunga Marine Reserve, Kenya. In. Coral Ree Degradation in the Indian Ocean Status Report 2002, $47-54$

Obura, D.O. (in review) Coral recruitment, size class structure and diversity as indicators of ree resilience in the Kiunga Marine Reserve,
Obura, D.O., Furaha, J., Mwaura, J. (2005) Cora settlement patterns in the Mombasa Marine National Park. CORDIO Status Report 2005. Pp 167-173.

Richmond, R.H. (1987) Energetics, competency, and long distance dispersal of planulae larvae of the coral Pocillopora damicornis. Marine Biology 93, 527-533

Samoilys, M.S. (1988) Abundance and species richness of coral reef fish on the Kenyan coast: the effects of protective management and fishing. In: Proceedings of the $6^{\text {th }}$ Internation and fishing. In: Proceedings of the 6 International Coral Ree Symp C.R.C. (2003) Predicted 1.261-266

Sheppard, C.R.C. (2003) Predicted recurrences of mass coral mortality in the Indian Ocean. Nature 425, 294-297

Sheppard, C.R.C. \& Wells, S.M. (1988) Coral Reefs of the World. Volume 2: Indian Ocean, Red Sea and Gulf pp 1 \pm 389 . UNEP Regional Seas Directories and Bibliographies. IUCN, Gland and UNEP, Nairobi.

Tamelander, J. (2002) Coral recruitment following mass mortality event. Ambio 31, 551-557

Ward, S. \& Harrison, P.L. (1996) The effects of elevated nutrients on settlement of coral larvae during the ENCORE experiment, Great Barrier Reef, Australia. Proceedings of the $8^{\text {th }}$ International Coral Reef Symposium 2, 891-896

Wilkinson, C, Linden, O, Cesar, H, Hodgson, G, Rubens, J, Strong, A (1999) Ecological and socioeconomic impacts of 1998 coral mortality in the Indian Ocean: An ENSO impact and a warning of future change? Ambio 28: 188-196 